\title{
Relationship Between the 6-minute Walk Test and Correlates of Type 2 Diabetes: Indication for caution in exercise prescription
}

\author{
Adeniyi, A.F. ${ }^{1}$, Uloko, A.E. ${ }^{2}$, Sani-Suleiman, I. $^{3}$ \\ ${ }^{1}$ Department of Physiotherapy, College of Medicine, University of Ibadan, Ibadan, Nigeria \\ ${ }^{2}$ Department of Medicine, Aminu Kano Teaching Hospital, Kano, Nigeria \\ ${ }^{3}$ Department of Physiotherapy, Bayero University, Kano, Nigeria \\ Correspondence
}

Dr. A.F. Adeniyi, Department of Physiotherapy, College of Medicine, University of Ibadan, Ibadan, Nigeria

•Email: adeniyifatai@yahoo.co.uk; fadeniyi@comui.edu.ng

\section{SUMMARY}

Physical exercise is adjudged effective in the prevention and co-management of Type 2 diabetes (T2D). However, because of the different levels of exercise capacity; it must be prescribed with caution based on the individual's peculiarities. The link between the 6-minute walk test and some correlates of T2D was investigated.

This cross-sectional study of 58 consenting patients with $\mathrm{T} 2 \mathrm{D}$ was conducted at the diabetes clinic of a secondary health centre in Kano, Nigeria. The measurements included the 6-Minute Walk Distance (6MWD) for exercise capacity and the T2D correlates including age, body mass index, waist circumference and waist-hip ratio. The relationships between the parameters were determined using the Pearson's correlation coefficient at a significance level of 0.05 .

The participants consisted of 36 males $(62.1 \%)$ and 22 females $(37.9 \%)$. The mean $6 \mathrm{MWD}$ for males was $302 \pm 33.28$ meters and was shorter in women. The $6 \mathrm{MWD}$ correlated significantly $(\mathrm{P}<0.05)$ with each of age $[\mathrm{r}=-0.78$ (males), -0.62 (females)], waist circumference $[\mathrm{r}=-0.82$ (males), -0.77 (females) $]$ and body mass index $[\mathrm{r}=-0.66$ (males), -0.74 (females) $]$, while the waist hip ratio correlated significantly with the $6 \mathrm{M} \mathrm{WD}$ only in the male participants $(\mathrm{r}=-0.59)$.

Low exercise capacity in patients with T2D was associated with higher age and adiposity. Prescription of physical exercise to patients with T2D who present with one or a combination of these variables should be done with care in order not to exceed safe limits.

KEY WORDS: type 2 diabetes, physical exercise, age, body mass index, waist circumference and waist-hip ratio

\section{INTRODUCTION}

Exercise is considered a cornerstone of diabetes management, along with diet and medication (Sigal et al. 2004). As a consequence of the mounting body of evidence on the positive effects of physical exercise in the management of type 2 diabetes (T2D), it is usually prescribed for patients from many sources, including health workers, support groups, the internet and magazines; as well as many other non-scientific sources. Many of these sources, however, lack the skill, experience, and knowledge required for safe exercise prescriptions and implementation for diabetics (Mullooly and Kemmis, 2005). According to Sigal et al. (2004), before embarking on a programme of physical activity more vigorous than brisk walking, people with diabetes should be assessed for the risk of coronary events. These would include persons aged over 40 , with or without cardiovascular disease risk factors other than diabetes; persons aged over 30 with type 1 or type 2 diabetes of more than 10 years duration; persons with hypertension, dyslipidaemia, proliferative or preproliferative retinopathy, nephropathy, including microalbuminuria; and cigarette smokers. Others according to Sigal et al. (2004) are persons with known or suspected coronary artery disease, cerebrovascular disease, and/or peripheral vascular disease, autonomic neuropathy and advanced nephropathy with renal failure. Assessments of some of these risk factors are costly and may not be readily available. However, a cluster of adiposity and demographic variables may also influence the risks of developing coronary events, which are also correlated with T2D. These variables include age, gender (Franse et al., 2001), waist circumference, waist hip ratio (Behan and 
Mbizo 2007), and body mass index (Lyssenko et al., 2005); and are easily measured in the clinic or home settings. The relationship between the exercise capacity of patients with T2D and these easily measured variables are however not clearly understood. In addition, documented studies are scarce. In this preliminary study, therefore, the relationships between the 6-minute walk test and each of the correlates of $\mathrm{T} 2 \mathrm{D}$, including age, waist circumference, waist hip ratio and body mass index were investigated. The 6-minute walk test is used as a measure of the functional exercise capacity of individuals and was considered in this study because it is a simple test of exercise capacity (ATS 2002) similar to normal daily activity and can be conducted easily in the clinic.

\section{METHODOLOGY}

This cross-sectional investigation of patients with T2D was conducted at the Diabetes Clinic of the Murtala Mohammed Specialist Hospital, Kano, where ethical approval was sought and obtained. The study was introduced to all the patients with T2D attending the clinic on their respective clinic days and the participants were requested to indicate their willingness to participate after detailed briefing on the requirements for the study. The set eligibility criteria included a diagnosis of T2D without any associated apparent cardiovascular disorders such as cardiac dysfunction and hypertension, with no positive response to any question on the Physical Activity Readiness Questionnaire (PAR-Q) and willingness to give informed consent and participate in the 6-minute walk test. The PAR-Q assessed the self-reported fitness of the individuals for the exercise test. Any individual who answered positive to any of the questions was excluded. Out of the 133 T2D patients attending the Diabetes Clinic, only 58 (aged 20-60 years) agreed to participate in the study and met the inclusion criteria.

The 6-minute walk test was performed along a $50 \mathrm{~m}$ long flat, straight, well-ventilated corridor, free of obstacles and according to the procedure described by the American Thoracic Society (2002). The test measured the distance that a patient could walk quickly on a flat, hard surface in 6 minutes and it evaluated the global and integrated responses of all the systems involved during the exercise, such as the pulmonary and cardiovascular systems, systemic circulation, peripheral circulation, blood, neuromuscular units, and muscle metabolism (ATS 2002). The main outcome was the distance covered in six minutes of selfselected comfortable walking pace labelled the 6-minute walk distance. Other assessments included the age, body mass index, waist circumference, waist hip-ratio, duration of diabetes and the fasting blood glucose. The data was analysed using the mean, standard deviations and Pearson's correlation coefficient at 0.05 level of significance.

\section{RESULTS}

The participants comprised 36 males (62.1\%) and 22 females $(37.9 \%)$. The mean 6MWD for males was $302 \pm$ 33.28 meters and was shorter in women $(288 \pm 42.56)$. In males, the mean fasting blood glucose, duration of diabetes, and body mass index were $8.72 \pm 2.43 \mathrm{mmol} / \mathrm{l}$, $7.56 \pm 2.11$ years and $26.92 \pm 4.36 \mathrm{Kg} / \mathrm{m}^{2}$ while the means of the waist circumference for the male and female participants were $101.81 \pm 7.65 \mathrm{~cm}$ and $97.62 \pm 10.18 \mathrm{~cm}$ respectively (table 1$)$. The $6 \mathrm{MWD}$ significantly $(\mathrm{P}<0.05)$ correlated with each of age $[\mathrm{r}=-0.78$ (males), -0.62 (females)], waist circumference $[\mathrm{r}=-0.82$ (males), -0.77 (females)], BMI [ $\mathrm{r}=-0.66$ (males), -0.74 (females)] while the waist hip ratio correlated significantly with the $6 \mathrm{MWD}$ only in the male participants $(r=-0.59)$ (table 2). The fasting blood glucose also inversely correlated with the 6MWD in both males and females $(\mathrm{P}<0.01)$. The duration of diabetes however did not correlate with 6MWD (P > 0.05 ) in both the male and female participants.

Table 1. Mean values of the variables studied

\begin{tabular}{lll}
\hline & $\begin{array}{l}\text { Males } \\
(\mathrm{n}=36) \\
\text { Mean } \pm \mathrm{SD}\end{array}$ & $\begin{array}{l}\text { Females } \\
(\mathrm{n}=22) \\
\text { Mean } \pm \mathrm{SD}\end{array}$ \\
\hline Age (years) & $48.47 \pm 11.5$ & $53.11 \pm 6.72$ \\
Body mass index $\left(\mathrm{Kg} / \mathrm{m}^{2}\right)$ & $26.92 \pm 4.36$ & $29.55 \pm 5.23$ \\
$\begin{array}{l}\text { Waist circumference }(\mathrm{cm}) \\
\text { Waist hip ratio }\end{array}$ & $101.81 \pm 7.65$ & $97.62 \pm 10.18$ \\
$\begin{array}{l}\text { Fasting blood glucose } \\
\text { (mmol/l) }\end{array}$ & $0.97 \pm 0.07$ & $0.85 \pm 0.03$ \\
$\begin{array}{l}\text { Duration of diabetes } \\
\text { (years) }\end{array}$ & $7.56 \pm 2.11$ & $10.82 \pm 3.11$ \\
$\begin{array}{l}\text { 6 minute walk distance } \\
\text { (m) }\end{array}$ & $302 \pm 33.28$ & 2.43 \\
\hline
\end{tabular}

Note: $\mathrm{SD}=$ standard deviation 
Table 2. Relationship between the 6 minute walk distance and correlates of Type 2 Diabetes

\begin{tabular}{|c|c|c|c|c|c|c|c|}
\hline & $6 \mathrm{MWD}$ & Age & FBG & BMI & WC & WHR & Duration of diab. \\
\hline Pearson's r & $(\mathrm{M}, \mathrm{F})$ & $(\mathrm{M}, \mathrm{F})$ & $(\mathrm{M}, \mathrm{F})$ & $(\mathrm{M}, \mathrm{F})$ & $(\mathrm{M}, \mathrm{F})$ & $(\mathrm{M}, \mathrm{F})$ & $(\mathrm{M}, \mathrm{F})$ \\
\hline 6MWD & $(1,1)$ & & & & & & \\
\hline Age & $\left({ }^{*}-0.58, *-0.62\right)$ & $(1,1)$ & & & & & \\
\hline FBG & $(\dagger-0.71, \dagger-0.82)$ & $(0.27,0.30)$ & $(1,1)$ & & & & \\
\hline BMI & $(*-0.66,-\dagger 0.74)$ & $(*-0.65, * 0.59)$ & $(\dagger 0.82, \dagger 0.78)$ & $(1,1)$ & & & \\
\hline WC & $(\dagger-0.82, \dagger-0.77)$ & $\left({ }^{*} 0.53, * 0.58\right)$ & $(\dagger 0.79, \dagger 0.81)$ & $\left({ }^{*} 0.72, \dagger 0.84\right)$ & $(1,1)$ & & \\
\hline WHR & $\left({ }^{*}-0.59,-0.27\right)$ & $\left(0.36,{ }^{*} 0.52\right)$ & $\left({ }^{*} 0.65, \dagger 0.72\right)$ & $(0.48, * 0.56)$ & $(\dagger 0.81, \dagger 0.79)$ & $(1,1)$ & \\
\hline Duration of diabetes & $(-0.19,-0.46)$ & $(† 0.88, \dagger 0.85)$ & $(0.31,0.40)$ & $(0.36, * 0.58)$ & $(-0.44, *-0.62)$ & $(-0.20,-0.22)$ & $(1,1)$ \\
\hline
\end{tabular}

Notes: ${ }^{*}$ Significant at $\mathrm{p}<0.05 ; \dagger$ Significant at $\mathrm{p}<0.01$

$(\mathrm{M}, \mathrm{F})=($ Male, Female $) ; 6 \mathrm{MWD}=6$ Minute Walk Distance; FBG = Fasting Blood Glucose; BMI = Body Mass Index; WC = Waist Circumference; WHR $=$ Waist Hip ratio

\section{DISCUSSION}

The exercise capacity (assessed by the 6MWD) of the participants was found to be far below what was documented as reference values for apparently healthy adults above 20 years which ranged from 474 to 1,040, with an average of $698 \pm 96$ meters (Gibbons et al., 2001). It was also found that high fasting blood glucose, increasing age, increasing waist circumference, increasing waist hip ratio and higher body mass index were related to lower exercise capacity in the sample of patients with T2D based on the 6MWD. It was however noted that the duration of diabetes did not correlate significantly with the $6 \mathrm{MWD}$. The clinical implication of this finding is that regardless of the duration of diabetes, prescription of physical exercise to patients with T2D who are older, with poor glycaemic control and with high values of body mass index, waist circumference and waist hip ratio has to be done with caution in view of the low-exercise capacity of these individuals.

The poor exercise capacity of patients with T2D based on the 6MWD may be because of the link between T2D and adverse cardiac effects (Devereux et al., 2000). The high prevalence of pulmonary embolism and hypertension found in patients with T2D (Movahed et al., 2005) could also explain this low exercise capacity. Age related systemic changes (Tolep and Kelson, 1993), the extra demand imposed by excessive weight and adiposity (Enright and Sherill 1998), and glucose abnormalities (Suskin et al. 2000) may also contribute to low exercise capacity. The low exercise capacity may also have adverse consequences for the T2D patients during exercise. In a study by Wei et al. (2000), after adjustment for age, baseline cardiovascular disease, hypercholesterolaemia, hypertriglyceridaemia, body mass index, hypertension, parental cardiovascular disease, smoking, and baseline fasting glucose levels, lowfit diabetic men had a 2.2 -fold greater mortality risk compared with men with moderate or high fitness. Hence, it is necessary to recognize the potential value of maximal exercise testing for the purposes of setting appropriate exercise intensities and assessing physical capacity and prognosis (Sigal et al., 2002).

The low exercise capacity presented by the participants in this study may not necessarily be due only to the variables investigated in this study. There could be a number of confounding factors that were not accounted for in the study. These may include underlying cardiovascular disease, dyslipidaemia and a history of smoking. However, the moderate to high correlations observed may indicate a possible contribution of these variables to the low exercise capacity of these patients. Shortage of literature on the 6 minute walk test specifically in persons with diabetes made comparison with previous studies somewhat difficult.

In conclusion, the fact that low exercise capacity in patients with T2D is associated with higher age, higher adiposity and poor glycaemic control may necessitate a limit to the intensity at which these categories of patients should exercise. These factors should be given due consideration when prescribing exercises for patients with T2D. Further investigation into the exercise capacity of patients with T2D based on the 6-minute walk test and its relationship with both invasive and non-invasive correlates of diabetes is recommended.

\section{References}

American Thoracic Society (ATS). 2002. Statement: Guidelines for the six-minute walk test. American Journal of Respiratory and Critical Care Medicine 166: 111 - 117.

Behan, KJ and Mbizo J. 2007. The relationship between waist circumference and biomarkers for diabetes and CVD in healthy non-obese women. The Pensacola Study. Laboratory Medicine 38: 422-427. 
Devereux R.B., M.J. Roman, M. Paranicas, M.J. O’Grady, E.T.Lee, T.K. Welty, R.R. Fabsitz, D. Robbins, E.R, Rhoades and B.V. Howard. 2000. Impact of diabetes on cardiac structure and function: The strong heart study. Circulation 101: 2271- 2276.

Enright P.L. and D.L. Sherrill. 1998. Reference equations for the six-minute walk in healthy adults. American Journal of Respiratory and Critical Care Medicine 158: 1384-1387.

Franse L.V., M. Di Bari, R..I. Shorr, H.E Resnick, J.T. van Eijk, D.C. Bauer, A.B. Newman , and M. Pahor. 2001. Type 2 diabetes in older well-functioning people: Who is undiagnosed? Data from the Health, Aging, and Body Composition Study. Diabetes Care 24: 2065 - 2070.

Gibbons W.J., N. Fruchter, S. Sloan and R.D. Levy. 2001. Reference Values for a Multiple Repetition 6-Minute Walk Test in healthy adults older than 20 years. Journal of Cardiopulmonary Rehabilitation 21: 87-93.

Lyssenko V. P. Almgren, D. Anevski, R. Perfekt, K. Lahti, M. Nissen, B.Isomaa, B. Forsen, N. Homstrom, C. Saloranta, M.R. Taskinen, L. Groop, T. Tuomi. 2005. Predictors of and longitudinal changes in insulin sensitivity and secretion preceding onset of Type 2 Diabetes. Diabetes 54: 166-174.

Movahed M., M. Hashemzadeh and M.M. Jamal. 2005. The prevalence of pulmonary embolism and p u $1 \mathrm{~m}$ o n a r y hypertension in patients with Type II Diabetes Mellitus. Chest 128: 3568 - 3571.

Mullooly C.A. and K.L. Kemmis. 2005. Diabetes educators and the exercise prescription. Diabetes Spectrum 18: 108 - 113.

Sigal R.J., G.P. Kenny, D.H. Wasserman and C. CastanedaSceppa. 2004. Physical Activity/Exercise and Type 2 Diabetes. Diabetes Care 27: 2518- 2539.

Suskin N., R.S.McKelvie, R.J. Burns, R. Latini, D. Pericak., J. Probstfield, J.L. Rouleau, C. Sigouin, C.B.Solymoss, R. Tsuyuki, M. White and S. Yusuf. 2000. Glucose and insulin abnormalities relate to functional capacity in patients with congestive heart failure. European Heart Journal 21: 13681375.

Tolep K. and S.G.Kelsen. 1993. Effect of aging on respiratory skeletal muscles. Clinics in Chest Medicine 3: 363-378.

Wei M, L.W.Gibbons, J.B. Kampert, M.Z. Nichaman and S.N. Blair. 2000. Low cardiorespiratory fitness and physical inactivity as predictors of mortality in men with type 2 diabetes. Annals of Internal Medicine 132: 605 - 611. 